\title{
Perceptions of motivation and willingness to participate in randomized clinical trials in emergency obstetric and newborn care among survivors of severe obstetric complications
}

\author{
Daniel Kabonge Kaye ( $\nabla$ dankkaye@yahoo.com ) \\ Makerere University College of Health Sciences https://orcid.org/0000-0003-1490-859X \\ Gershom Chongwe \\ School of Public Health, University of Zambia, P.O. Box 50110, Lusaka, Zambia \\ Nelson K. Sewankambo \\ Makerere University College of Health Sciences \\ Joseph Ali \\ Johns Hopkins University Berman Institute of Bioethics \\ Adnan A. Hyder \\ Johns Hopkins University Berman Institute of Bioethics \\ Nancy E Kass \\ Johns Hopkins University Berman Institute of Bioethics
}

Research article

Keywords: Randomized clinical trials, Emergency obstetric and newborn care, Informed consent, Research participation, Research engagement, Willingness to participate in research, Trust

Posted Date: June 13th, 2020

DOI: https://doi.org/10.21203/rs.3.rs-32900/v1

License: (c) (i) This work is licensed under a Creative Commons Attribution 4.0 International License. Read Full License 


\section{Abstract \\ Background}

Previous studies have shown that participants in emergency research may not understand the research and therefore may not make informed decisions to participate. Little is documented about motivation for research participation in randomized clinical trials in emergency obstetric and newborn care. Conducted among survivors of severe obstetric complications, this study sought to assess beliefs, perceptions and values as well as motivation and willingness for participation in research.

\section{Methods}

This was a qualitative study conducted among 18 survivors of severe obstetric complications who were attending the postnatal clinic of Kawempe National Referral Hospital, Uganda. The participants were contacted 6-8 weeks after surviving severe obstetric complications during pregnancy or childbirth. Eighteen in-depth interviews were conducted from June 1 to July 6,2019 . The issues explored included interviewees' perceptions and beliefs regarding 1) what constitutes clinical trial research in emergence obstetric and newborn care, 2) the purpose and necessity to conduct such research, 3) how emergency research-related information should be delivered to potential participants and their caregivers, 4) why women would be willing and motivated to participate in this type of research, and 5) the potential benefits and risks to research participants. Data were analyzed according to themes using the constant comparative method.

\section{Findings:}

Many respondents were potentially willing to participate in research during obstetric emergencies, even when there was no possibility of material or therapeutic benefit, provided there was reasonable assurance that there would be no harm to them or (more especially) to their babies. Both solidarity and communitarian consent were important influences on motivation to participate in clinical trials in emergency obstetric care. Motivation to participate in research was partly related to the desire to access care, to contribute to knowledge about pregnancy complications, to possibility of material or therapeutic benefit, to perceived low level of risk particularly to the baby, to trust in the investigators and to opportunity to receive research results.

\section{Conclusion}

Solidarity, communitarian consent, perceived level of potential risk, possibility of benefit and trust in the investigators were the major potential motivators for participation in research in the emergency obstetric and newborn care context.

\section{Background}

In pregnancy and perinatal emergency contexts, obtaining informed consent for randomized clinical trials (RCTs) may be complicated by challenges related to information disclosure, comprehension and competence for voluntary authorization to participate. In the current best practice, written trial information often describes, among other things, the purpose, risks, potential benefits, and what will happen during the study; however, participants may not comprehend the information [1-3]. It may also not be clear to participants why they are expected to conduct themselves in a certain manner, or why they have to accept certain procedures to be performed in a stipulated manner [2,3]. What motivates prospective participants to consent for research in low- and middle-income countries (LMICs) may be related to how they understand the disclosed information. Informed consent to participate in research involves understanding of the purpose, benefits, risks and alternatives to participation, with clear differentiation between medical care and research, much as clinical research may entail involvement in clinical care-related activities [4, 5].

Page 2/18 
Several publications $[1,3,4,6,7-9]$ show that many participants may not understand research and therefore may not make informed decisions to participate. For instance, a study that assessed participant understanding of clinical trial information (three months after clinical trial enrollment) found that only $23 \%$ knew that treatment was randomly allocated, only $57 \%$ knew they might receive a placebo, and only $42 \%$ knew that adverse effects could occur [6]. Yet this study was conducted among participants who were not in a critical care context at the time of enrollment. Obtaining informed consent in emergency contexts is beset with several potential challenges related to failure to disclose information or failure to understand disclosed information about the research. Challenges include potential inability to communicate with (and obtain informed consent from) very sick, anxious, unconscious or sedated patients [7-9]. Also, critically ill patients' cognition may be compromised by the illness or the ongoing emergency treatment [7-9]. Such individuals are even less likely to comprehend or remember salient factors related to the research in which they participate and may lack the decisional capacity to give voluntary consent $[1,4,6,7-9]$.

The factors that influence willingness to participate in research in emergency obstetric and newborn care may include altruism and pre-formed decisions made prior to invitation to participate [10-16]. For instance, in a clinical trial in pediatric care, some participants went through the process of informed consent when they had already made up their minds to accept research participation [10], indicating that the disclosure of clinical trial information may have had little influence on their decisions or willingness to participate. This may be for altruistic reasons, therapeutic optimism or therapeutic misconception [11]. A systematic review of participation in a clinical trial by pregnant women [12] found that aspirational, collateral and direct benefits, third party influence, and absence of inconvenience were factors that facilitated decision `s to participate. In this study [12], barriers to participation included inconveniences, (perceived) potential risks, and lack of trust in the research enterprise. Altruistic reasons, therapeutic optimism and a desire to get information about their children's health are important factors that influence willingness and decisions by mothers (for their newborns) to participate in research [13]. For instance, in a newborn cohort study that investigated the theoretical acceptability and willingness of mothers to involve their newborns in clinical research [[13], altruistic reasons were the main driver given for the mothers' consent to research participation. The possibility that the mother would consent was higher if the child was healthy, if the clinical research was intended to solve a child's specific problem, and if the perceived study risks were low [13]. Also, the most important reasons for parents' acceptance of their children's participation in clinical investigations, in addition to altruism, was a need to learn more about their children's illness [14-16].

Theories that describe motivation include the incentive theory, humanistic theory, drive theory and expectancy theory [17]. The incentive theory suggests motivation depends on external rewards, and individuals intentionally pursue certain actions so as to gain rewards. The humanistic theory posits that individuals have strong cognitive reasons to perform various actions, according to the hierarchy of needs, which represents different motivations at different levels of need. In line with the drive theory of motivation, individuals are motivated to take certain actions so as to reduce internal tension from uncertainty caused by unmet needs (such as illness, fear of pregnancy complications or worries about making the correct decision regarding participation). The expectancy theory posits that when individuals think about the future, they formulate different expectations such that they actively pursue actions that enable them to achieve positive outcomes. In this study, in line with the above theories, motivation was defined as the compelling reason(s) an individual has for acting or behaving in a particular way in given circumstances, arising from within the individual (intrinsic motivation), or inspired by other people or events (extrinsic motivation). The theoretical framework for this study was the socio-ecological framework, which is suitable for analyzing motivation. An individual's motivation for enactment of a behavior may be influenced by intrinsic factors or extrinsic factors. Intrinsic factors are factors within the individual (such as personal need for healthcare or urge and desire to help others). The extrinsic factors also include interpersonal interactions with the healthcare system (in case of any health needs for self or for others), and interactions with immediate family contexts, community or society. This socio-ecological framework was used to assess personal factors (health status, knowledge, attitudes, perceptions, beliefs and misconceptions), interpersonal factors (influence of family and peers), community-level factors (institutional policies, practices and traditions) and society-level factors (such as legislation and healthcare policies). 
The socioecological framework recognizes that whereas individuals are responsible for enacting own behaviors, individual behavior is influenced by factors at different levels. The objective of this study was to gain a deeper understanding of factors that potentially motivate participation in obstetric and newborn clinical trials among survivors of obstetric complications in Uganda. This population theoretically could have been potential participants in emergency obstetric research if an opportunity to participate were available. We explored perceptions of survivors of obstetric complication on potential motivation and willingness to participate in randomized clinical trials in emergency obstetric and newborn care.

\section{Methods}

\section{Study setting and participants}

This phenomenological study was conducted in the postnatal clinic of Kawempe National Referral Hospital, a 450-bed specialized obstetrics and gynecology referral hospital in Kampala, Uganda, which serves as one of the public referral obstetric hospitals for Uganda. The hospital is also a research setting for several local and international clinical research projects, including clinical trials- conducted by graduate students and other researchers in Uganda. Consequently, many mothers are usually involved as participants in clinical research projects, though most of these are observation studies, as for ethical constraints, clinical trials in this populations are few. The study participants in this study were survivors of severe obstetric complications- where the mothers and newborns were at risk of morbidity or mortality- including severe preeclampsia/eclampsia, antepartum hemorrhage and obstructed labor. These women, who were attending the postnatal clinic at this hospital, were contacted 6-8 weeks after the obstetric events.

\section{Data collection procedure}

Data collection occurred from June 1 to July 6, 2019 and involved in-depth interviews with 18 survivors of severe obstetric complications (see Table 1) during their postnatal visit (at least 6 weeks after suffering severe obstetric complications during pregnancy or childbirth). The inclusion criteria were women aged 18 years or older, with history of severe obstetric complications, and providing informed consent for participation. Participants were purposefully selected on their routine appointments to the postnatal clinic. They were identified by both the research assistants and the investigator (DKK), after which they were given information about the study by the research assistants and invited to participate. To verify eligibility, the investigator assessed the patients' medical records to confirm that they had suffered a severe obstetric complication (severe preeclampsia, eclampsia, obstructed labor or obstetric hemorrhage during immediate prior pregnancy or childbirth). 
Table 1

Socio-demographic characteristics and clinical profiles of the 18 survivors of obstetric complications

\begin{tabular}{|c|c|c|c|c|c|c|c|c|}
\hline $\begin{array}{l}\text { Respondent } \\
\text { Number }\end{array}$ & Age & parity & $\begin{array}{l}\text { Highest } \\
\text { education } \\
\text { level } \\
\text { completed }\end{array}$ & $\begin{array}{l}\text { Marital } \\
\text { status }\end{array}$ & $\begin{array}{l}\text { Complications } \\
\text { constituting } \\
\text { severe } \\
\text { morbidity }\end{array}$ & $\begin{array}{l}\text { Management } \\
\text { instituted }\end{array}$ & $\begin{array}{l}\text { Willing to } \\
\text { participate } \\
\text { in } \\
\text { hypothetical } \\
\text { RCTs }\end{array}$ & $\begin{array}{l}\text { Would } \\
\text { permit } \\
\text { newborn } \\
\text { participation } \\
\text { in } \\
\text { hypothetical } \\
\text { RCT }\end{array}$ \\
\hline $\begin{array}{l}\text { Respondent } \\
1\end{array}$ & 23 & 3 & Primary & Married & $\begin{array}{l}\text { Antepartum } \\
\text { hemorrhage }\end{array}$ & $\begin{array}{l}\text { Emergency } \\
\text { caesarean } \\
\text { section }\end{array}$ & No & No \\
\hline $\begin{array}{l}\text { Respondent } \\
2\end{array}$ & 20 & 2 & Secondary & Married & Eclampsia & $\begin{array}{l}\text { Emergency } \\
\text { caesarean } \\
\text { section }\end{array}$ & Yes & No \\
\hline $\begin{array}{l}\text { Respondent } \\
3\end{array}$ & 34 & 5 & University & Married & $\begin{array}{l}\text { Postpartum } \\
\text { hemorrhage }\end{array}$ & $\begin{array}{l}\text { Blood } \\
\text { transfusion }\end{array}$ & Yes & No \\
\hline $\begin{array}{l}\text { Respondent } \\
4\end{array}$ & 23 & 4 & Primary & Married & $\begin{array}{l}\text { Antepartum } \\
\text { hemorrhage }\end{array}$ & $\begin{array}{l}\text { Blood } \\
\text { transfusion }\end{array}$ & Yes & No \\
\hline $\begin{array}{l}\text { Respondent } \\
5\end{array}$ & 19 & 1 & $\begin{array}{l}\text { No formal } \\
\text { education }\end{array}$ & Single & Eclampsia & $\begin{array}{l}\text { Emergency } \\
\text { caesarean } \\
\text { section }\end{array}$ & Yes & Yes \\
\hline $\begin{array}{l}\text { Respondent } \\
6\end{array}$ & 22 & 3 & Primary & married & $\begin{array}{l}\text { Antepartum } \\
\text { hemorrhage }\end{array}$ & $\begin{array}{l}\text { Blood } \\
\text { transfusion }\end{array}$ & No & No \\
\hline $\begin{array}{l}\text { Respondent } \\
7\end{array}$ & 19 & 2 & Primary & Single & $\begin{array}{l}\text { Severe } \\
\text { obstructed } \\
\text { labor }\end{array}$ & $\begin{array}{l}\text { Emergency } \\
\text { caesarean } \\
\text { section }\end{array}$ & No & No \\
\hline $\begin{array}{l}\text { Respondent } \\
8\end{array}$ & 27 & 3 & secondary & Married & $\begin{array}{l}\text { Antepartum } \\
\text { hemorrhage }\end{array}$ & $\begin{array}{l}\text { Blood } \\
\text { transfusion }\end{array}$ & No & No \\
\hline $\begin{array}{l}\text { Respondent } \\
9\end{array}$ & 24 & 4 & Secondary & Married & $\begin{array}{l}\text { Severe } \\
\text { obstructed } \\
\text { labor }\end{array}$ & $\begin{array}{l}\text { Emergency } \\
\text { caesarean } \\
\text { section }\end{array}$ & Yes & Yes \\
\hline $\begin{array}{l}\text { Respondent } \\
10\end{array}$ & 20 & 2 & Secondary & Single & $\begin{array}{l}\text { Severe } \\
\text { obstructed } \\
\text { labor }\end{array}$ & $\begin{array}{l}\text { Emergency } \\
\text { caesarean } \\
\text { section }\end{array}$ & No & No \\
\hline $\begin{array}{l}\text { Respondent } \\
11\end{array}$ & 18 & 1 & Secondary & Single & Preeclampsia & $\begin{array}{l}\text { Emergency } \\
\text { caesarean } \\
\text { section }\end{array}$ & Yes & Yes \\
\hline $\begin{array}{l}\text { Respondent } \\
12\end{array}$ & 25 & 3 & Primary & Married & $\begin{array}{l}\text { Postpartum } \\
\text { hemorrhage }\end{array}$ & $\begin{array}{l}\text { Blood } \\
\text { transfusion }\end{array}$ & Yes & Yes \\
\hline $\begin{array}{l}\text { Respondent } \\
13\end{array}$ & 29 & 6 & primary & Married & $\begin{array}{l}\text { Postpartum } \\
\text { hemorrhage }\end{array}$ & $\begin{array}{l}\text { Blood } \\
\text { transfusion }\end{array}$ & Yes & No \\
\hline $\begin{array}{l}\text { Respondent } \\
14\end{array}$ & 34 & 7 & Secondary & Married & $\begin{array}{l}\text { Antepartum } \\
\text { and } \\
\text { postpartum } \\
\text { hemorrhage }\end{array}$ & $\begin{array}{l}\text { Blood } \\
\text { transfusion }\end{array}$ & No & No \\
\hline $\begin{array}{l}\text { Respondent } \\
15\end{array}$ & 23 & 2 & Primary & Single & Preeclampsia & $\begin{array}{l}\text { Emergency } \\
\text { caesarean } \\
\text { section }\end{array}$ & Yes & Yes \\
\hline $\begin{array}{l}\text { Respondent } \\
16\end{array}$ & 28 & 3 & University & Married & $\begin{array}{l}\text { Acute kidney } \\
\text { injury }\end{array}$ & Dialysis & Yes & No \\
\hline
\end{tabular}




\begin{tabular}{|lllllllll|}
\hline $\begin{array}{l}\text { Respondent } \\
\text { Number }\end{array}$ & Age & parity & $\begin{array}{l}\text { Highest } \\
\text { education } \\
\text { level } \\
\text { completed }\end{array}$ & $\begin{array}{l}\text { Marital } \\
\text { status }\end{array}$ & $\begin{array}{l}\text { Complications } \\
\text { constituting } \\
\text { severe } \\
\text { morbidity }\end{array}$ & $\begin{array}{l}\text { Management } \\
\text { instituted }\end{array}$ & $\begin{array}{l}\text { Willing to } \\
\text { participate } \\
\text { in } \\
\text { hypothetical } \\
\text { RCTs }\end{array}$ & $\begin{array}{l}\text { Would } \\
\text { permit } \\
\text { newborn } \\
\text { participation } \\
\text { in } \\
\text { hypothetical } \\
\text { RCT }\end{array}$ \\
\hline $\begin{array}{l}\text { Respondent } \\
17\end{array}$ & 32 & 6 & Primary & Married & $\begin{array}{l}\text { Puerperal } \\
\text { sepsis }\end{array}$ & $\begin{array}{l}\text { Blood } \\
\text { transfusion }\end{array}$ & Yes & No \\
\hline $\begin{array}{l}\text { Respondent } \\
18\end{array}$ & 21 & 2 & $\begin{array}{l}\text { No formal } \\
\text { education }\end{array}$ & Married & $\begin{array}{l}\text { antepartum } \\
\text { hemorrhage }\end{array}$ & $\begin{array}{l}\text { Blood } \\
\text { transfusion }\end{array}$ & Yes & No \\
\hline
\end{tabular}

Potential participants provided written signed informed consent after being provided with detailed information about the study, which was reviewed verbally with each individual. Prospective participants were given assurance that they were free to decline, and that even if they declined, their decision would not affect the care that they were entitled to from the postnatal clinic. They were also assured that their information would be kept confidentially and no identifiable information would be revealed. A copy of the signed consent form was also provided to each participant. While all respondents understood both languages, the interviews were conducted in English for 12 participants, in Luganda only for 3 participants and both English and Luganda (3 interviews). With permission from study participants, the interviews were audio recorded and field notes were taken to provide an opportunity to document impressions, contexts, behaviors and nonverbal communications, which could be relevant to how participants understood research and what meanings they would attach to an invitation to take part in research during emergency obstetric and newborn care. For instance, from their voice tone, emotions and eagerness to respond, particularly on recalling the experiences at time of complications, one could surmise degree of willingness to participate if they had been invited to participate.

Issues explored, through semi-structured interviews included: 1) what constitutes clinical trial research in emergence obstetric and newborn care, 2) opinions and perceptions regarding the purpose and necessity to conduct such research, 3) perceptions on disclosure of trial information (how and when should participants be invited and how information about research participation should be given to potential participants), 4) what factors may affect comprehension of disclosed information (such as severity of disease, language use, decision aids, ways in which the information is presented, ease of reading the consent document, contextual factors such as research environment, privacy, confidentiality), 5) why women would be willing and motivated to participate in this type of research, and 6) the potential benefits and risks to research participants.

\section{Data analysis}

During data analysis, field notes provided important context to the interpretation of audio recordings of interviews from the non-verbalized communications, responses and behaviors. All audio recordings were transcribed verbatim and compared with field notes to add to the meanings stated in the responses. Once transcription was complete, transcripts were read carefully while listening to the audio recording so as to correct any areas that needed clarification. Other field information, such as pauses, laughter, looks of discomfort, as well any other contextual information that might have affected the participant were inserted into the transcripts, using periods such as punctuation, commas or full stops. The information in the transcripts was anonymized by deleting reference to names, places or significant events that could enable identification of the individual participants.

The transcripts were analyzed by thematic analysis described by Mays and Pope $[19,20]$. Data analysis was based on the constant comparative method [21-23] to analyze for codes or meaning units (recurrent patterns statements, words or phrases with similar meaning or interpretation) across data set [21-26]. The codes were aggregated into themes (groups of word patterns or phrases with similar meaning) to provide a description of the experience of the phenomenon (motivation 
and willingness to participate in randomized clinical trials during emergency obstetric care). Representative quotes from participants derived from the individual transcripts were included to illustrate the source of interpretations of information.

\section{Ethical considerations}

This research was reviewed and approved by the Makerere University School of Medicine Research and Ethics Committee (SOMREC) and Mulago Hospital Research and Ethics Committee. The Institutional Review Board of Johns Hopkins University School of Public Health relied on SOMREC as the IRB of record. Permission to conduct the study was also obtained from the Department of Obstetrics and Gynecology, Makerere University. As noted above, the study posed potential risk of psychological distress if individuals were reminded of unpleasant past experiences during their prior hospitalization with acute illness. Any information shared about unpleasant experiences from previous obstetric complications was received in an empathetic manner. Participants who seemed emotionally affected by recall of unpleasant experiences during pregnancy or childbirth were counseled.

\section{Findings}

\section{Motivation to participate in research}

All the women who were invited agreed to participate in the study. Table 1 shows the socio-demographic and clinical profiles of respondents. All these had severe obstetric complications that constituted the severe morbidity, which included severe obstructed labor, eclampsia and obstetric hemorrhage. All except two had completed at least primary level of education, three had participated prior in clinical trials for prevention of Mother-to-Child HIV transmission, and only 2 were primipara, indicating that they had prior experiences with the healthcare system before the index pregnancy or delivery where they developed obstetric complications.

Many survivors of pregnancy complications had the view that research about the cause of illness was necessary to obtain answers to many questions about pregnancy-related complications so as to develop new medications, to improve on existing medications, to examine the causes of illnesses or to identify how to improve the health of women during pregnancy, as exemplified by two respondents:

Respondent 7: "There is always a lot that is not known about illness in pregnancy. And sometimes emergencies occur suddenly. On one day you are fine, the next day you are very sick. Even doctors cannot explain why the diseases occur. It is necessary to find answers to those questions."

Respondent 2: "Finding out better ways of treating disease is good. Investigations provide answers to many questions about the disease. They are therefore necessary even when you know that gathering the evidence requires many pregnant women to be involved, even if it may lead to some dangers to pregnant women, with all the risks that (it) entails."

Some respondents, especially when asked about whether it is acceptable for them to be involved in those investigations, were of the view that in such emergency situations, investigations were not the priority. Rather, it was providing the necessary emergency care that was a priority, but acceptance would depend on how the information was communicated and on whether the mothers understood, as exemplified by two of the respondents.

Respondent 1: "There is often so much happening when you come in with a sick child. Moreover, this may occur when you have gone through a difficult pregnancy. You are worried about your baby. What you need then is treatment for both of you. There is no need to waste time on being involved in those investigations. Your health and that of the child take priority. Taking part in other activities is the last thing on your mind."

Respondent 2: "I wouldn't accept to take part. You should not go beyond your limits. If you (?) are already sick or your child is in danger, there is no reason to add on to that danger, unless there is hope of getting something better for you or your 
baby... I cannot even recommend what I do not support. Why would you take a risk if you don't have to, or if there is nothing to gain? But if they tell you more about what is involved, so that they explain carefully, ... then I can accept."

\section{Preferences regarding consent process}

Regarding how invitation to participate should be communicated, most respondents were of the view that this should be when they or the unborn babies were out of danger, and therefore when they could understand without what was referred to as "pressure", "stress" or "anxiety." The respondents preferred that the information would need to be simplified and brief, if they were to consider participating, as exemplified by two respondents:

Respondent 3: "You doctors have your difficult language. We don't understand it. At that time what I need is help and care. I have no time to listen or understand those "heavy" medical terms. What they tell me should be short and simple, so that if I have to ask my friends for opinion, I would be able to tell them exactly what they (research team) ask me to do."

Respondent 5: "They should give me time. They may come and give me information, but should give me a written summary to read on my own. If I can understand, then I may accept."

Most respondents were of the view that they needed time to understand the information given about research participation, and that researchers should assess whether they have understood the basics about the study, as demonstrated by two respondents:

Respondent 2: "You tell me about a new study that you want to do. If you want me to take part, I may mess your study. You need to test me to check if I have understood. Ask me a few questions about what I need to do and what you are going to do for me. If I answer correctly, then you guess that I have understood. If answers are wrong, then you repeat the information till I understand."

Respondent 5: "They should ask me, that okay, if you have understood, what is your role? What are you going to do? What do you understand? Remember, at that time, your brain is not 'steady' and you may be tired. They need to check if you will do the right thing that they want. If it is taking the medicine correctly, they ask how many tablets, at what time, and what else you will be doing."

Other respondents were of the view that the information about the research should be given privately or individually, rather than to everyone present, and participation should be confidential. Privacy and confidentiality were highly valued, as exemplified by one respondent:

Respondent 5: "They need to come to you and then ask, are you going to take part. That should concern only me. I may not want other people, even my relatives to know that I am involved."

Interviews explored whether randomization to different study groups, may influence trial acceptability. Most participants did not understand the reason or benefit of randomization. While seemingly in conflict with the concept of randomization, most respondents were of the view that the investigators would decide what was best for them, and therefore they would not mind the randomization procedures. Thus, to most participants, it was okay for the investigators to decide for them, and they trusted them to make the correct decisions for them. This misunderstanding signals trust in clinical researchers to do what is best for individual clinical trial participants regardless of methodological constraints such as the need for randomization, and is exemplified by two respondents:

Respondent 7: "I do not understand why doctors would let me belong to one or other group just by chance. But they know better what they need to find out. I believe they would do the right thing. If what they do makes me belong to a particular group, I have no objection." 
Respondent 5: "I think even when doctors say you should belong to this or that group, they know the best. For me what would matter is that they do the right thing. I believe they are called to serve. I have a feeling most doctors still know what is right and that is what they do for patients. Much as I do not understand how they would do it or why, I would believe that is the right thing if they did it."

\section{Solidarity and communal consent}

The community played an integral role in the uptake and acceptability of clinical trials amongst respondents. Patient decision-making was intimately tied to the relationship with others in their local community, whose advice was considered important for the decision whether or not to participate. This is exemplified by three respondents:

Respondent 1: "I have ever looked after a mother who was involved in something like that (participated in an HIV drugs trial during pregnancy). Before joining, we discussed the ideas and thought it would be a good thing. So we advised her to participate. At least even if there was not much good or benefit, there was nothing she would lose. So even for me, I would participate if invited, but I may need to consult my friends first."

Respondents 3: "I would ask myself, is this a good thing for me? If I am convinced, I would go ahead. If I have doubts, I would ask my friends or family members. Depending on their opinion, I would make a decision to join or not."

Respondent 4: "It depends on how they convince me as to what I may benefit. Where I am not sure, I would ask for more time while I consult my friends or other patients. I may even call some nurses or family doctor. If they know better, what they advise to do is what I may take as the right decision. I think even if they were in my position, that is what they would do...If they asked me for advice, I would give it".

Most respondents considered the advice of family members and friends as very crucial in decision-making, especially in emergency situations. A number of participants reported that the benefits of the trial should be available to everyone involved, including other patients and community members, so because of that, their advice regarding participation was necessary. This would place the need for high standard of health care to be extended towards the patients in the investigation and that other community members would guarantee that the correct things are done. Members in the community, not only those involved in the study, would share the blame rather than the individual alone if something went wrong, as exemplified by one respondent.

Respondent 3: "If the purpose if generating information to help science, then it should not be a personal responsibility but a responsibility of everybody. This means that even the community members, the health facility managers and local political leaders should have a say about which investigations are acceptable... If they gave a green light prior, then that makes it easy for me to accept invitation to participate. Because then I know the major concerns that I may also have would have been addressed."

The local political leaders and other trusted members in the community were thought to have a significant influence on clinical trial acceptability. When the local leader or influential person (such as a nurse or doctor) is trusted by the community members and this individual approves the trial, the potential study participants will be much more comfortable with the invitation and (making own) decision to participate in the clinical trial. The prior acceptance by the community, especially the influential members, that such investigations should be conducted is a guarantee for easier acceptance and motivation to participate in the clinical trial. Similarly, this prior acceptance reduces the likelihood of declining further participation or default by participants (such as loss to follow up) from the clinical trial requirements as exemplified by other respondents:

Respondent 6: "Our leaders are sometimes good and consider what is important for us. ... / believe they all have the best interests of patients on their mind as they deliberate about accepting such a study to be done."

Respondent 9: "You can ask other nurses or doctors first for their opinion. If they are not sure about the study, you may decline immediately. If they are somehow positive, you may consider whether you can join. It all depending (sic) on how 
they approach you and what you think is important for you."

Respondent 5: "If you have an opportunity to ask those already in the study, this can help you to make a decision. They can explain what is going on and what is involved (what participation involve. But you have to consider and make your own decision. If there is positive advice from your doctor or nurses, then there is no need for many questions."

\section{Benefits, risks and compensation for research-related harms}

Most participants were of the view that participation should involve possibility of personal benefit for them, their unborn baby or the newborn at birth. Regarding potential benefits, the respondents suggested that they expect individualized care, better care or some medications if they agreed to participate, as exemplified by two respondents:

Respondent 1: "They have to convince me that it is a good idea. They need to talk to me in a language I understand best, not English. I expect that they would provide me with better care. For instance, get me the drugs I need, or give me better attention."

Respondent 7: "At least they should contribute to some of my expenses like on drugs or food. They have to assure me that there is something to gain for me or my baby... I need to later be able to say, yes, taking part was a good idea. I want a higher standard of care if I participate. This can only be if I am better off than those who do not take part."

For many respondents, hope for benefit was a significant motivation for clinical trial participation. This is exemplified by the following respondents:

Respondent 1: "I had to buy most of the drugs. If you are very sick, they (doctors and nurses) tell you buy this and that medicine, that it will make you get better. Before the research study, when you visit the government hospital, you pay for the tests, you buy the medicines and sometimes you do not have the money. If they can provide the drugs I need, then I would take part. That may save me some of the expenses."

Respondent 6: "I would not hesitate to participate if they offer me help. That may be my only chance. The (study) nurses may provide some drugs that I could not afford. I am grateful that both my child and I are okay now. Some friends lost their babies. If taking part in the study solves the medical problem, then why not?"

While most participants could be motivated by the need to help other mothers (without possibility of personal benefit), they were not willing to accept the invitation unless their newborns were to benefit, that is, they were unwilling to participate in research for the sake of generating information to help other newborns. This is demonstrated by the respondents below:

Respondent 6: "Maybe for myself I can accept participation even if I may not benefit, as long as my participation could benefit other women so that they do not suffer like me. However, where my baby is involved, I cannot do anything like that. I can't participate for the sake of helping others."

Respondent 14: "Sometimes you hear rumors that those involved in research are given free drugs and they pay for the laboratory tests and other investigations. If they invited me and I knew they offered these, then I would not hesitate to join."

Respondent 11: "I would not have a problem making the decision (to participate in research). But many times, you take part but you never know what has come out of the blood and other samples they take. If I were to know the results, then I would take part... Even if I may not personally benefit, I would need to know the results... If it is for my baby to take part, I would not accept, unless my child is to benefit."

Other respondents suggested that participation would depend on how they were approached and how the invitation to participate was presented. A prior positive relationship cultivated with them by health workers would make it easier for them to make the decision to participate. This is exemplified by two respondents below: 
Respondent 16: "It depends on how they approach me. If they are helpful with good manners, then I can accept. At times, you may go to the hospital and they ignore you, mistreat you or don't help even when you call for help. Why should I join their studies? But If joining is my hope for getting help, I cannot hesitate to join

Respondent 15: "Some health workers are good, they are kind, they are supportive. If they could tell you to do something, you just accept because of their approach."

Regarding potential burdens or risks, respondents suggested that participation may lead to spending a longer period of time in the health facility as researchers complete the study, or due to some unexpected harm. Where there may be a possibility of significant harm, most respondents would either hesitate to participate, or would decline the invitation to continue participation, as exemplified by two respondents:

Respondent 8: "You never know what happens. If they give you medication that is not fully tested, the baby may be affected. Even me I may get complications. In that case I will have to decline or may leave their study."

Respondent 6: "They may keep you longer in hospital because they still want you to do this or that procedure, taking off more blood, doing more checks on you. If what they tell me involves any of that, then I would not join. I would not want unnecessary delays."

Respondents were highly influenced whether or not to participate by whether there would be risks for their baby. Risks to the mother herself were secondary, in comparison. The main reason for giving the baby priority was that the baby needs to be able to grow optimally and survive the pregnancy. Most respondents reported that they would tolerate more risk than they would tolerate for the baby, as exemplified by several respondents:

Respondent 6: "As a mother I would accept quite a lot for that myself. Unless the risks are really dangerous. For my baby, there are a lot of things that I will not accept under all circumstances. However, if the danger is on my baby, then I will not accept. I would hesitate."

Respondent 8: "I have no reason to refuse. At least if they assure me that what the study involves will not hurt my baby... They have to convince me that I will benefit. The information they tell me should be clear to me... Whatever procedures they will do (should be) safe for me and my baby. If am convinced, I can then be involved."

Respondent 4: "There is never an acceptable risk for my pregnancy. Never. I cannot accept to participate just to satisfy someone's interests. A pregnant woman and her baby should be very much protected in our society. After all, a pregnancy is like an illness itself... I can understand that that the results may help me or others. But my interests and my concerns are more important."

For research that involved invasive research procedures, women were willing to accept procedures that included blood draws or caesarean section among the study procedures, provided they were assured of safety for them or their unborn baby. However, they needed guarantees that these procedures have a clear medical indication and would be similar to procedures that are undertaken in case of obstetric emergencies. This is exemplified by three respondents:

Respondent 1: "I am sure many women suffer the same problem I had. If (taking part in research) can put my baby in danger, I cannot accept. I would not accept anything that they are just trying out... May be some risk for me is acceptable, but for my baby, the danger should be zero if I am to accept for the sake of benefitting others. .. cannot accept treatment chosen by chance or lottery. It should be medicine that works...I think many would also do the same (accept to take part in research) to help other women".

Respondent 6: "When I remember what I went through, I think it is important to help others in that critical period to also have this joy, to be able to appreciate my happiness that I went through this period well... There may be some danger. But if there

Page $11 / 18$ 
is hope, then I would accept and go through it... May be this is God's way of using me to help others... But I would leave immediately if I suspect some serious danger to my baby,"

Respondent 3: "I had to buy most of the medications. Even many investigations (like the ultrasound scan) were not free. If the participation may provide you a chance to have someone else meet these costs, then I would willingly participate."

On the issue of whether there should be compensation for adverse events or harms that may arise during the research, most respondents were of the view that it is the responsibility of investigators to plan and provide compensation, regardless of whether harms that eventuate were foreseeable. Participants were more concerned about harms or injuries that may cause death or disability (either serious or permanent). Respondents perceived that the responsibility of compensation should be guaranteed by the community or health facilities and should be enforceable. Monetary compensation, provision of treatment for the adverse event, or both, were thought necessary and the type of response was thought to depend on the circumstances and nature of the complication. In the absence of an appropriate response, respondents believe that researchers should be held responsible and could even be sued to obtain the compensation. This is exemplified by two respondents:

Respondent 1: "If the investigators suspect that my life may be put in danger, they should be ready for compensation by treating me or my baby, and even pay me some money for the trouble caused to me. ... The society should guarantee that this happens and should put the investigators to task if they fail."

Respondent 7: "They find me with my illness and want me to get involved. They should compensate me in case of problems. If not, they should leave me alone. They should not add to my trouble, or else we end up in court."

\section{Discussion}

This study found that perceived level of risk to the unborn baby or newborn, in comparison to perceived potential risk to the mother, had more influence on motivation and willingness to participate in clinical trials in the emergence obstetric and newborn care setting. Secondly, hope of some benefit, either therapeutic or material, heavily influences decisions for clinical trial participation. Thirdly, community solidarity and community decision-making influence individual decisions. Depending on the context, the degree of influence may be persuasive enough to affect independent process of the decision to participate, thereby affecting voluntariness for trial participation. Lastly, contextual factors, particularly poor access to needed health services and trust in the healthcare system influence motivation and willingness for clinical trial participation.

The findings are in agreement with findings of a systematic review on facilitators and barriers for pregnant women's participation in research [12], which found that (aspirational, direct and collateral) benefits, third-party influence and absence of inconvenience were facilitators, while lack of trust in research, perceived risks and third-party influence were barriers. Similarly, a study that investigated reasons why women may consent to have their newborns participate in pediatric research [13] found three main predictors: perceived importance of the study, perceived benefits and low perceived risk (if risk to the fetus is minimal, participation may be acceptable). Likewise, from the socio-ecological framework, diverse factors acting at different levels influence decisions for clinical trial acceptability or continuing trial participation $[11,12,13$, $28,29]$.

\section{The perceived influence of the community in motivation for clinical trial participation}

The perceived influence of the community in motivation for clinical trial participation suggests that the community level is a major potential locus of decision-making for research participation in emergency obstetric and newborn care. This locus operates through influence on clinical trial acceptability in general and influence on willingness or motivation for individual

Page $12 / 18$ 
trial participation. The nature of influence may be such that it affects an individual's ability to process the information in line with their own preferences and values. In that way, the influence poses a potential threat to voluntariness for research participation. The influence may affect appreciation (recognition of the nature, meaning and significance of the decision to participate); reasoning (the ability to process the information and derive conclusions, including ability to weigh risks, benefits and evaluate potential consequences) and values (or ability to recognize and express consistent and stable set of ideals that guide reasoning on the process of making choices). The effect on voluntariness does not mean that potential participants should neither seek or value what others think about the participation decision nor count that influence as essential towards their motivation to participate. However, the influence becomes critical if (in a situation where one knows what others think about their decision), individuals cannot make an independent decision or do not feel that they own the decision afterwards. In this perspective, individuals may find themselves compelled by circumstances or external pressure to make decisions which may be contrary to their ideals, values and preferences, much as the decision is independent (that is, the ultimate decision to make the choice was theirs).

In addition, the perception of clinical trial participation as 'benefit-sharing' may impede individual choice with regard to balancing risks and benefits prior to decisions for enrolment. Individuals may find themselves compelled by the need for some material or therapeutic benefits, though the ultimate decision remains in their power. A community or health facility's failure to balance the provision of care with opportunities for clinical trial participation to the patients (or their caregivers) could lead to an 'empty choice' (where clinical trial participation is practically only one viable option) [28]. This situation could occur where structural factors related to challenges in healthcare (such as absence of basic medications) impede balanced decision making [28, 30, 31].

The emergency obstetric care research context apparently has potential to affect both voluntariness, particularly in emergency situation where life is usually at stake and decisions may need to be urgently made regarding clinical trial participation. Any influence on understanding ultimately affects decision-making, even if it may not affect autonomy, competence or voluntariness. Such influence includes basic understanding (comprehension of the facts involved in that decision); appreciation (insight' into the circumstances of a given decision, that is, recognition of the nature, meaning and significance of the decision); reasoning (the ability to process the information and derive conclusions including ability to weigh risks, benefits and evaluate potential consequences); choice (availability of choices and ability to express or communicate the intended decision or choice); or values (ability to recognize and express minimally consistent and stable set of values to guide reasoning on the process of making choices). The influence, if inappropriate may be potentially manipulative or persuasive for mothers in emergency contexts, and thus may negatively or positively influence participation in clinical trials, and potentially influence discontinuation. The ethical guidelines $[4,6,7]$ require that a decision to participate should not be unduly influenced by other factors, and that clinical trial-related information should be disclosed, there should be comprehension, and potential participants should use this information to process risks, benefits and alternatives, and that individuals should make an independent decision in line with their preferences and values. The study findings that many potential participants either do not understand randomization or don't care about its implications are an apparent contradiction to the requirements of regulations and guidelines which require understanding of the process of randomization in clinical trials.

The expectations of the community and study context to influence clinical trial participation has been reported in prior studies [10-13]. For instance, in a mixed methods study nested in a malaria vaccine trial [10], over $60 \%$ of mothers accepted because of free medication where the initial sources of information were neighbors or friends for over $60 \%$ of respondents. Similarly, over $95 \%$ of 342 respondents had already made a decision to participate by the time they were interviewed, and over $85 \%$ indicated intentions to participate if asked [10]. The study findings suggest that while employing culturally appropriate means of engaging potential research participants prior to or during may be challenging, it may be more appropriate and acceptable for research in emergency obstetric care contexts [29]. This may involve community engagement, harnessing communitarian consent and nurturing solidarity.

Page $13 / 18$ 
Communal decision-making goes beyond traditional philosophical and ethical notions of autonomy and informed consent, to acknowledge influence of significant "others" in the decision-making for clinical trial participation in certain contexts [29, $36,37]$. This recognition acknowledges that respondents are embedded in communal lives, where other members of the community contribute to the health and welfare of others, and therefore could contribute to decision-making about healthcare seeking [36], and thus, to clinical trial participation. Communal decision-making acknowledges that individuals are also social persons who reside within a particular socio-cultural context, which influences those individuals' viewpoints as well as their normative set of values and ideals, including those values regarding decisions for and the informed consent process for research participation [36]. This is not ethically problematic (does not compromise voluntariness for research participation) as long as individuals remain with the option to make the final decisions regarding research participation.

An individual-based informed consent model may be problematic in settings and contexts where norms of decision-making emphasize communal decisions and solidarity rather than individual autonomy [29, 36, 37]. Each individual may have their own understanding of who they are, what they value, how they and others should be treated as people, and what important relationships need to be honored [36]. Similarly, each individual may have his/her specific views about disease and illness, with related fears, concerns and unanswered questions [36]. While individuals may have different ways of interpreting consent, disease and illness, communal views, values and questions regarding illness, ill-health and research may influence research participation [37].

\section{Solidarity and motivation for research participation in emergency obstetric care}

Much as solidarity is not well utilized in bioethics [38], it may be an important consideration, as much as altruism, for research participation in emergency obstetric and newborn care [39]. Ter Meulem [40] presents solidarity as the degree of social cohesion in a group or society whereby individuals, because of various motivations, are willing to serve and promote the collective interest of the group or of society. The possibility of willingness to participate in research without possibility of potential benefit, yet with conviction that others may be helped, and expectation of others to do the same at a time of need, represents more of solidarity rather than social capital, altruism or mere reciprocity. Willingness to support the greater good (as part of solidarity) does not impose on individuals a moral imperative to do so [40] and neither does it impose an imperative to accept the influence of others. There are reports that informed consent for community research in many areas of sub-Saharan Africa is communal [41] and a manifestation of solidarity. Solidarity refers to the shared vulnerabilities of where community members engender initiatives for helping them to address unmet needs, including bearing costs of assisting others regarded as similar [42]. It represents disposition to call for-and expect- assistance when in need [42] when faced by shared risks, vulnerabilities and opportunities [43. In this study, much as women would participate in research (to generate information that might help others, even where they themselves would not benefit), they had concerns about the health of their children during research participation, and expressed no interest in joining simply for the sake of helping others especially if participation could put the baby at risk. This solidarity may motivate individuals to decline enrolment or ongoing participation, in cases of mistrust or miscommunication about trials [32,44-46]. Solidarity affirms that individuals have agency and power $[47,48]$ to accept or refuse the influence of others in line with their preferences and values.

\section{Conclusion}

Many women who suffered pregnancy complications were potentially willing to participate in research during emergency obstetric care. Motivations for participations include possibility of benefit for others or baby, but for altruism and solidarity only if the mother were to participate with assurances of no potential harm to the pregnancy or newborn. Trust in the investigators was a strong perceived predictor of willingness to participate in research. Thus, investigators should be mindful of this and consider whether research poses any additional risk (beyond the risk of usual obstetrical complexity to the pregnancy or newborns) when they discuss research with potential participants in the emergency obstetric and newborn care context. Irrespective of whether the research addresses maternal, fetal or newborn problems, researchers should

Page $14 / 18$ 
employ measures that reduce potential risks (as well as maximize potential benefits) of participation to women, the unborn babies or the newborns. Secondly, investigators ought to employ strategies to foster, employ or strengthen culturally appropriate means of engaging potential research participants prior to or during enrollment, including solidarity and community consent. Thirdly, investigators should prioritize building trust in the healthcare system (and in research itself), by addressing research problems that address perceived community needs and through maintaining professional credibility.

\section{Declarations}

\section{Ethics approval and consent to participate}

This research was approved by the Research and Ethics Committee of Makerere University School of Medicine, and Mulago Hospital Research and Ethics Committee as well as permission from the Department of Obstetrics and Gynecology, Makerere University. Participation in this research was voluntary and respondents provided informed consent. Prospective participants were given assurance that they were free participate and that even if they declined, their decision would not affect the due care that they were entitled to. They were also assured that the information collected from them would be kept confidentially and no identifier information would be revealed. Permission was obtained from the participants to have the interview proceedings audio recorded, with assurance that the recordings were only for research purposes and were to be kept confidentially. The study posed potential risk of psychological harm if potential participants or participants were reminded of unpleasant past experiences during their prior hospitalization with acute illness. All the communication with potential participants was done in a respectful and professional manner, and any information about the unpleasant experiences of obstetric complication was made in an empathetic manner.

\section{Consent for publication}

Not applicable

\section{Availability of data and material}

The data is available on request from the corresponding author

\section{Competing interests}

The authors declare that they have competing interests

\section{Authors' contributions}

DKK conceptualized the study, conducted the literature review, did the data collection and drafted the manuscript. JA, NEK, NKS and AAH were mentors on the project and contributed to the study design, advised on data collection and analysis, and reviewed manuscript drafts. GC provided advice on the research design and development of data collection instruments. All authors reviewed all versions including the final manuscript draft.

\section{Funding}

DKK completed this study as a post-doctoral fellow of the Fogarty African Bioethics Consortium, Post-doctoral Fellowship Program (FABC-PDF) with support from the Fogarty International Center of the U.S. National Institutes of Health under award number D43TW010512. The views are solely the responsibility of the authors and do not necessarily represent the official views of the National Institutes of Health. NKS is also Director of the IHRET Training program supported by $\mathrm{NIH} /$ Fogarty grant number 5R25TW009730.

\section{Acknowledgements}


The authors are grateful for access to the e-resources of Johns Hopkins University and to the research participants and research assistants (for data collection) and the manuscript peer reviewers for their constructive comments.

\section{References}

1. Schmidt TA, Salo D, Hughes JA, Abbott JT, Geiderman JM, Johnson CX, et al. Confronting the ethical challenges to informed consent in emergency medicine research. Acad Emerg Med. 2004;11:1082-9.

2. Shafiq N, Malhotra S. Ethics in clinical research: Need for assessing comprehension of informed consent form? Contemporary Clinical Trials. 2011;32:169-72.

3. Helmreich RJ, Hundley V, Norman A, Ighedosa J, Chow E. Research in pregnant women: the challenges of informed consent. NursWomens Health. 2007;11(6):576-85.

4. Vanpee D, Gillet JB, Dupuis M. Clinical trials in an emergency setting: implications from the fifth version of the Declaration of Helsinki. J Emerg Med. 2004;26(1):127-31.

5. Emanuel EJ, Wendler D, Grady C. What makes clinical research ethical? JAMA. 2000;283(20):2701-11.

6. Hereu P, Pérez E, Fuentes I, Vidal X, Suñé P, Arnau JM. Consent in clinical trials: what do patients know? Contemp Clin Trials. 2010;31(5):443-6.

7. Biros MH, Lewis RJ, Olson CM, Runge JW, Cummins RO, Fost N. Informed consent in emergency research. Consensus statement from the Coalition Conference of Acute Resuscitation and Critical Care Researchers. JAMA. 1995; 273(16):1283-1287.

8. Smischney NJ, Onigkeit JA, Hinds RF, Nicholson WT. Re-evaluating ethical concerns in planned emergency research involving critically ill patients: an interpretation of the guidance document from the United States Food and Drug Administration. J Clin Ethics. 2015;26:61-7.

9. Helmreich RJ, Hundley V, Norman A, Ighedosa J, Chow E. Research in pregnant women: the challenges of informed consent. Nurs Womens Health. 2007;11(6):576-85.

10. Pare Toe L, Ravinetto RM, Dierickx S, et al. Could the decision of trial participation precede the informed consent process? Evidence from Burkina Faso. PLoS ONE. 2013;8:e80800.

11. Miller FG, Brody H. A critique of clinical equipoise. Therapeutic misconception in the ethics of clinical trials. Hastings Cent Rep. 2003;33:19-28.

12. van der Zande ISE, van der Graaf R, Hooft $L$, van Delden. Facilitators and barriers to pregnant women's participation in research: A systematic review. Women Birth. 2018;31(5):350-61.

13. Tait AR, Voepel-Lewis T, Malviya S. Participation of children in clinical research: factors that influence a parent's decision to consent. Anesthesiology. 2003;99(4):819-25.

14. Vecchi Brumatti L, Montico M, Russian S, Tognin V, Bin M, Barbone F, et al. Analysis of motivations that lead women to participate (or not) in a newborn cohort study. BMC Pediatr. 2013;13:53.

15. Maayan-Metzger A, Kedem-Friedrich P, Kuint J. Motivations of mothers to enroll their newborn infants in general clinical research on well-infant care and development. Pediatrics. 2008;121:e590-6.

16. Tait AR, Voepel-Lewis T, Siewert M, Malviya S. Factors that influence parents' decisions to consent to their child's participation in clinical anesthesia research. Anesth Analg. 1998;86:50.

17. Cherry K. Theories. of motivation. https://www.verywellmind.com/theories-of-motivation-2795720. Accessed March 18, 2019.

18. Mays N, Pope C. Qualitative research in health care. Assessing quality in qualitative research. BMJ. 2000;320(7226):50-2.

19. Pope C, Ziebland S, Mays N. Qualitative research in health care. Analysing qualitative data. BMJ. 2000;320(7227):1146. 
20. Wong LP. Data analysis in qualitative research: a brief guide to using NVivo. Malaysian Family Physician. 2008;3(1):14-20.

21. Smith JA. Beyond the divide between cognition and discourse: using interpretative phenomenological analysis in health psychology. Psychol Health. 1996;11(2):261-71.

22. Basit TN. Manual or electronic? The role of coding in qualitative data analysis. Educational Research. 2003;45(2):14354.

23. Patton MQ. Qualitative Research \& Evaluation Methods. Page 114. 3rd Edition. Thousand Oaks, Californa: Sage; 2002.

24. Sutton J, Austin Z. Qualitative research: Data collection, analysis, and management. Can J Hosp Pharm. 2015;68(3):226-31.

25. Larkin M, Watts S, Clifton E. Giving voice and making sense in interpretative phenomenological analysis. Qual Res Psychol. 2006;3(2):102-20.

26. Chuan VT, Schaefer GO. Research in Resource-Poor Countries [Internet]. The Hastings Center. 2015. (Available from: https://www.thehastingscenter.org/briefingbook/multinationa I-research/) [Accessed November 20, 2018].

27. 24. Hayden C. Taking as giving: bioscience, exchange, and the politics of benefit-sharing. Soc Stud Sci 2007: 37: 72958.

28. Kingori P. The. "empty choice": a sociological examination of choosing medical research participation in resourcelimited Sub-Saharan Africa. Curr Sociol. 2015;63:763-78.

29. Fisher JA. Expanding the frame of "voluntariness" in informed consent: structural coercion and the power of social and economic context. Kennedy Inst Ethics J. 2013;23:355-79.

30. Molyneux CS, Peshu N, Marsh K. Trust and informed consent: insights from community members on the Kenyan coast. Soc Sci Med. 2005;61:1463-73.

31. Kenyon S. Participating in a trial in a critical situation: a qualitative study in pregnancy. Qual Saf Health Care. 2006;15:98-101.

32. Oude Rengerink K, Logtenberg S, Hooft L, Bossuyt PM, Mol BW. Pregnant women' concerns when invited to a randomized trial: a qualitative case control study. BMC Pregnancy Childbirth. 2015;15:207.

33. Rodger MA, Sc M, Makropoulos D, Sc B, Walker M, Keely E, et al. Participation of pregnant women in clinical trials: will they participate and why? Am J Perinatol. 2003;20(2):69-76.

34. Callahan D. Individual good and common good: a communitarian approach to bioethics. Perspect Biol Med. 2003;46:496-507.

35. Marsh VM, Kamuya DK, Parker MJ, Molyneux CS. Working with concepts: the role of community in international collaborative biomedical research. Public Health Ethics 2011: 4: 26-39.

36. Harmon SH. Solidarity: a (new) ethic for global health policy Health Care Anal. 2006 Dec;14(4):215-36.

37. ter Meulen R. Solidarity, justice, and recognition of the other. Theor Med Bioeth. 2016;37:517-29.

38. Ijsselmuiden CB, Kass NE, Sewankambo KN, Lavery JV. Evolving values in ethics and global health research. Glob Public Health. 2010;5(2):154-63.

39. Krogstad DJ, Diop S, Diallo A, Mzayek F, Keating J, Koita OA, et al. Informed consent in international research: the rationale for different approaches. Am J Trop Med Hyg. 2010;83:743-7.

40. Gould CC. Solidarity and the problem of structural injustice in healthcare. Bioethics. 2018;32(9):541-52. ..

41. Grietens KP, Ribera JM, Erhart A, Hoibak S, O'Neill S, Dierickx S, et al. The importance of blood is infinite: conceptions of blood as life force, rumours and fear of trial participation in a fulani village in rural Gambia. PLoS One. 2016;11(8):e0160464.

42. Ravinetto M, Gryseels C, et al. Doctors and vampires in sub-Saharan Africa: ethical challenges in clinical trial research. Am J Trop Med Hyg. 2014;91:213-5. 
43. Chadwick R, Berg K. Solidarity and equity: new ethical frameworks for genetic databases. Nat Rev Genet. 2001;2:31821.

44. Ahola-Launonen J. Humanity and Social Responsibility, Solidarity, and Social Rights. Camb Q Healthc Ethics. 2016;25(2):176-85.

45. Wendler D, Shah S. Involving communities in deciding what benefits they receive in multinational research. J Med Philos. 2015;40(5):584-600.

46. Jennings B. Solidarity and care as relational practices. Bioethics. 2018;32(9):553-61.

47. Eckenwiler L. Displacement and solidarity: An ethic of place-making. Bioethics. 2018;32(9):562-8.

48. Thom DH, Kravitz RL, Bell RA, Krupat E, Azari R. Patient trust in the physician: relationship to patient requests. Fam Pract. 2002;19(5):476-83. 